Personalidade Acadêmica Homenageada:

Augustus B. Cochran III (Agnes Scott College)

\title{
A VINCULAÇÃO DO PRINCÍPIO PROCESSUAL DA NÃO-SURPRESA E A APLICAÇÃO DA LEI DE INTRODUÇÃO ÀS NORMAS DO DIREITO BRASILEIRO - LINDB
}

\section{BINDING OF THE PROCEDURAL PRINCIPLE OF NON-SURPRISE AND THE APPLICATION OF THE LAW OF INTRODUCTION TO THE NORMS OF BRAZILIAN LAW - LINDB}

\section{FABRICCIO PETRELI TAROSSO}

Advogado e Mestrando no Programa de Mestrado da UNICURITIBA.

\section{RESUMO}

O presente artigo pretende aproximar alguns conceitos da novel Lei de Introdução às Normas do Direito Brasileiro - LINDB ao princípio da não-surpresa aplicável ao processo tributário, seja ele Administrativo ou Judicial. A Lei Federal n. 13.655 de 25/04/2018 houve por incluir no Decreto-Lei o 4.657, de 4 de setembro de 1942 Lei de Introdução às Normas do Direito Brasileiro - disposições sobre segurança jurídica e eficiência na criação e na aplicação do direito público. Deste modo, muitas dúvidas têm surgido acerca da convivência entre a regra geral de direito tributário, inserta no Art. 144 do Código Tributário Nacional, de que a lei vigente à época dos fatos geradores deve ser levada em conta ao deslinde de uma questão e que a jurisprudência majoritária à época dos mesmos fatos - se modificada - não deve servir de parâmetro para a tomada das decisões.

PALAVRAS-CHAVE: Lei de Introdução às Normas do Direito Brasileiro - LINDB; Princípio Processual da não-surpresa 
Personalidade Acadêmica Homenageada:

Augustus B. Cochran III (Agnes Scott College)

\section{ABSTRACT}

The present article intends to approximate some concepts of the novel Law of Introduction to the Norms of Brazilian Law - LINDB to the principle of non-surprise applicable to the tax process, be it Administrative or Judicial. Federal Law n. 13,655 dated 04/25/2018, there was a need to include in Decree-Law No. 4.657, dated September 4, 1942 - Law on Introduction to the Rules of Brazilian Law - provisions on legal certainty and efficiency in the creation and application of public law. In this way, many doubts have arisen about the coexistence between the general rule of tax law, inserted in Article 144 of the National Tax Code, that the law in force at the time of the generating facts must be taken into account in the definition of an issue and that the majority case-law at the time of the same facts - if modified - should not serve as a parameter for decision-making. The study will have as a method the legal and bibliographical research on the subject.

KEYWORDS: Law of Introduction to the Norms of Brazilian Law - LINDB; Procedural Principle of Non-Surprise

\section{JUSTIFICATIVA PARA O TEMA E INTRODUÇÃO}

Antes de tudo, cabe pontuar que o presente opúsculo nada mais é do que um despretensioso ensaio visando propor alguns apontamentos acerca da recente alteração da Lei de Introdução às Normas do Direito Brasileiro - LINDB, Lei Federal n. 13.655 de 25/04/2018 que pretendeu incluir no Decreto-Lei no 4.657 , de 4 de setembro de 1942 disposições sobre segurança jurídica e eficiência na criação e na aplicação do direito público.

Como se verá, ao buscar introduzir dispositivos na Lei de Introdução, essa novel legislação, sob o pretexto de dispor sobre segurança jurídica, houve por tocar em conceitos caros ao emprego do direito público, tais como praticidade das decisões administrativas e judiciais, motivação do ato administrativo decisório, aplicação da Lei no tempo, ato jurídico perfeito e direito adquirido, estabilidade do 
Personalidade Acadêmica Homenageada:

Augustus B. Cochran III (Agnes Scott College)

trânsito em julgado, seja das decisões tomadas na esfera administrativa seja das judiciais.

Apesar de recente, a legislação em comento já tem sido alvo de diversas e acaloradas discussões, talvez justamente por alcançar esses pontos considerados nevrálgicos ao Direito Público, afetando não só a relação jurídica que se trava entre particulares, mas especialmente aquela que envolve a participação do Ente Estatal, em qualquer âmbito de jurisdição.

De todo modo, o objetivo a que se destina o presente estudo é perquirir-se a respeito da relação que pode existir entre o princípio da não-surpresa em matéria processual e a aplicabilidade da LINDB no ao Direito Tributário.

\section{BREVÍSSIMO REGISTRO DA EVOLUÇÃO LEGISLATIVA}

O Decreto-Lei n. 4.657 de 4 de setembro de 1942, intitulado, em sua redação original, de "Lei de Introdução ao Código Civil Brasileiro" sofreu, ao longo dos anos, algumas modificações, dentre elas a alteração pela Lei № 12.376 de 2010 que ajustou a própria ementa para "Lei de Introdução às normas do Direito Brasileiro", numa denotação de que as disposições da referida normal legal não mais disporiam somente acerca das relações travadas entre particulares - regidas pelo Direito Civil - mas também àquelas que envolvem o Poder Público, ou seja, que interessam particularmente ao Direito Administrativo.

Todavia, pra fins de delimitação da reflexão que este conciso estudo propõe, será enfocado o mencionado Decreto-Lei n. 4.657/42 com as alterações a ele feitas pela Lei 13.655 de 25/04/2018, esta, como se disse, ostentado a alcunha de "nova" Lei de Introdução às normas do Direito Brasileiro.

\section{ALGUNS CONCEITOS QUE A "NOVA" LINDB PROCUROU AGASALHAR}

Artigos legais introduzidos recentemente na LINDB trouxeram uma nova 


\title{
Personalidade Acadêmica Homenageada: \\ Augustus B. Cochran III (Agnes Scott College)
}

proposta de entendimento acerca do alcance dos efeitos da coisa julgada, na esfera administrativa.

Nesse sentido, os Artigos 20 e 23:

\begin{abstract}
Art. 20. Nas esferas administrativa, controladora e judicial, não se decidirá com base em valores jurídicos abstratos sem que sejam consideradas as consequências práticas da decisão. Parágrafo único. A motivação demonstrará a necessidade e a adequação da medida imposta ou da invalidação de ato, contrato, ajuste, processo ou norma administrativa, inclusive em face das possíveis alternativas.". Art. 23. A decisão administrativa, controladora ou judicial que estabelecer interpretação ou orientação nova sobre norma de conteúdo indeterminado, impondo novo dever ou novo condicionamento de direito, deverá prever regime de transição quando indispensável para que o novo dever ou condicionamento de direito seja cumprido de modo proporcional, equânime e eficiente e sem prejuízo aos interesses gerais. Com efeito, a atuação do administrador, que pode ser definida pelo contrato social, não exige, necessariamente que este seja sócio da pessoa jurídica.
\end{abstract}

O artigo 20 parece trazer mais racionalidade às decisões proferidas seja na esfera administrativa como na judicial, posto que sugere ao julgador que, ao proferir seu decisum, tenha em conta os aspectos práticos (consequências). Também toca, referido dispositivo, num ponto relevante que é a fundamentação (motivação) das decisões.

Nesse sentido, aliás, não se pode furtar ao registro que o Código de Processo Civil (Lei Federal ํo 13.105, de 16 de março de 2015) contempla um conceito de fundamentação:

Art. 489: (...) $\S 1^{0}$ - Não se considera fundamentada qualquer decisão judicial, seja ela interlocutória, sentença ou acórdão, que: I - se limitar à indicação, à reprodução ou à paráfrase de ato normativo, sem explicar sua relação com a causa ou a questão decidida; II - empregar conceitos jurídicos indeterminados, sem explicar o motivo concreto de sua incidência no caso; III - invocar motivos que se prestariam a justificar qualquer outra decisão; IV - não enfrentar todos os argumentos deduzidos no processo capazes de, em tese, infirmar a conclusão adotada pelo julgador; V - se limitar a invocar precedente ou enunciado de súmula, sem identificar seus fundamentos determinantes nem demonstrar que o caso sob julgamento se ajusta àqueles fundamentos; VI - deixar de seguir enunciado de súmula, jurisprudência ou precedente invocado pela parte, sem demonstrar a existência de distinção no caso em julgamento ou a superação do entendimento. 
Personalidade Acadêmica Homenageada:

Augustus B. Cochran III (Agnes Scott College)

O CPC/2015, em seu Art. 15, dispõe sobre sua aplicação - supletiva e subsidiária ao Processo Administrativo.

Art. 15. $\mathrm{Na}$ ausência de normas que regulem processos eleitorais, trabalhistas ou administrativos, as disposições deste Código lhes serão aplicadas supletiva e subsidiariamente.

Para Alberto Xavier, se todo o procedimento fiscal está submetido ao princípio da fundamentação, isto significa que todos os atos e decisões que compõem seu iter devem estar estribados em expressa fundamentação legal e fática, sob pena de invalidade. ${ }^{1}$

James Marins, por sua vez, entende que: ${ }^{2}$

O primado da fundamentação está relacionado com o princípio do formalismo moderado, pois, embora deva ser reduzida a formalidade do ato ou da decisão administrativa, deve obedecer a critérios lógicos e assegurar o mínimo de formalismo necessário para que se conheça suficientemente seus supedâneos legais e fáticos; a fundamentação obrigatória está também relacionada com o princípio da motivação, que é princípio constitucional geral da Administração Pública, com a diferença que no campo procedimental e processual não haverá espaço para registros fáticos de conveniência e oportunidade que são próprios da atividade discricionária e não se coadunam com o caráter vinculado do procedimento e do Processo Administrativo.

Com efeito, a observância do princípio da fundamentação das decisões administrativas é, sem dúvida, uma das formas de garantir a aplicação de outros dois primados não menos relevantes: o do contraditório e ampla defesa, previstos expressamente no art. 5o-, inciso LV da Constituição Federal de 1988:

LV - aos litigantes, em processo judicial ou administrativo, e aos acusados

\footnotetext{
1 Do lançamento - Teoria geral do ato, do procedimento e do processo tributário. São Paulo: Forense, 1998, p. 113.

2 Direito Processual Tributário Brasileiro. Administrativo e Judicial. 2 ed. em e-book baseada na 10.

Ed. Impressa. Sai Paulo: Revista dos Tribunais, 2017, p. 10.
} 


\title{
Personalidade Acadêmica Homenageada:
}

Augustus B. Cochran III (Agnes Scott College)

em geral são assegurados o contraditório e ampla defesa, com os meios e recursos a ela inerentes.

Outro ponto relevante que a LINDB traz - que, a rigor, é o cerne de reflexão deste breve estudo - é o contido em seu art. 24:

\begin{abstract}
Art. 24. A revisão, nas esferas administrativa, controladora ou judicial, quanto à validade de ato, contrato, ajuste, processo ou norma administrativa cuja produção já se houver completado levará em conta as orientações gerais da época, sendo vedado que, com base em mudança posterior de orientação geral, se declarem inválidas situações plenamente constituídas.

Parágrafo único. Consideram-se orientações gerais as interpretações e especificações contidas em atos públicos de caráter geral ou em jurisprudência judicial ou administrativa majoritária, e ainda as adotadas por prática administrativa reiterada e de amplo conhecimento público.
\end{abstract}

Curioso observar, de início, que o caput referido procurou estabelecer critérios para interpretação, aplicação, vigência e eficácia das leis em geral, tanto no campo do Direito Privado como no campo do Direito Público.

No que tange à leitura do Direito Material, a questão da vigência das leis, no tempo, sempre teve como norte a observância do Art. $1^{\circ}$ do já mencionado DecretoLei o 4.657 , de 4 de setembro de 1942, cujo artigo permanece com a mesma redação mesmo após o advento da "nova" LINDB, qual seja de que "Salvo disposição contrária, a lei começa a vigorar em todo o país quarenta e cinco dias depois de oficialmente publicada".

Em matéria tributária, no entanto, o Artigo 144 do Código Tributário Nacional (Lei Federal ํㅜ 5.172, de 25/10/1966) tem a seguinte a diç̧ão:

Art. 144. O lançamento reporta-se à data da ocorrência do fato gerador da obrigação e rege-se pela lei então vigente, ainda que posteriormente modificada ou revogada.

Desse confronto entre o Art. 24 da LINDB e o Art. 144 do CTN, surge uma reflexão, pela qual haja, talvez, um aparente conflito, qual seja de que o Art. 24 da LINDB pode ensejar uma interpretação no sentido de que, ainda que a legislação à época dos fatos possa comportar um entendimento, para o deslinde da questão 
Personalidade Acadêmica Homenageada:

Augustus B. Cochran III (Agnes Scott College)

deve ser considerada a jurisprudência majoritária também da época dos mesmos fatos - e não a jurisprudência majoritária atual (época do julgamento).

Este parece ser um importante paradigma que se instaurou com o advento da "nova" LINDB.

E nesse ponto, há uma questão que parece relevante suscitar, que é justamente a dúvida acerca de que se o julgador, ao considerar a jurisprudência dominante à época dos fatos que ensejaram a obrigação tributária - e não aquela contemporânea à própria decisão - não estaria, talvez por vias indiretas, contribuindo para uma decisão surpresa.

\section{PRINCÍPIO PROCESSUAL DA NÃO-SURPRESA}

Nesse particular, uma das inovações trazidas pelo já citado Código de Processo Civil foi a expressa previsão do princípio da vedação às decisõessurpresa, previsto no artigo 10:

O juiz não pode decidir, em grau algum de jurisdição, com base em fundamento a respeito do qual não se tenha dado às partes oportunidade de se manifestar, ainda que se trate de matéria sobre a qual deva decidir de ofício.

Naturalmente que referido dispositivo parece guardar consonância com as garantias constitucionais do devido processo legal (art. 50, caput e inciso LIV) e do contraditório (inciso LV do mesmo artigo) ao vedar que juiz ou tribunal decidam qualquer questão sem que seja dado às partes se manifestarem sobre ela.

A esse respeito, Cássio Scarpinella Bueno ${ }^{3}$ entende que:

O art. 10, aplicando (e desenvolvendo) o que se pode extrair do art. 9º quer

\footnotetext{
${ }^{3}$ Manual de Direito Processual Civil, São Paulo; Saraiva, 2015, p. 89.
} 
Personalidade Acadêmica Homenageada:

Augustus B. Cochran III (Agnes Scott College)

evitar o proferimento das chamadas 'decisões-surpresa', isto é, aquelas decisões proferidas pelo magistrado sem que tenha permitido previamente às partes a oportunidade de influenciar sua decisão e, mais do que isso, sem permitir a elas que tivessem conhecimento de que decisão como aquela poderia vir a ser proferida

Além do artigo 10, o CPC de 2015 traz outros dispositivos com a mesma intenção, quais sejam o parágrafo único do artigo 493 que: "Se constatar de ofício o fato novo, o juiz ouvirá as partes sobre ele antes de decidir”; e o parágrafo $5^{0}$ do artigo 921: "O juiz, depois de ouvidas as partes, no prazo de 15 (quinze) dias, poderá, de ofício, reconhecer a prescrição de que trata 0 \& $4^{\circ}$ e extinguir $o$ processo".

Possível notar que a pretensão do códex processual civil em vigor parece não admitir, em hipótese alguma, que o julgador possa impor surpresa aos litigantes, decidindo um ponto jurídico sem que às partes seja dado se manifestar.

Com o passar do tempo, essa discussão foi judicializada e chegou ao Superior Tribunal de Justiça que, por intermédio de sua $3^{\underline{a}}$ Turma, no julgamento do Recurso Especial n. 1.725.225-SP, de relatoria do ministro Paulo de Tarso Sanseverino, declarou a nulidade de acórdão proferido pelo Tribunal de Justiça de São Paulo, reconhecendo a deserção do recurso de apelação em razão de insuficiência do preparo. No caso analisado, embora o intimado o recorrente a complementar as custas processuais, referida intimação deixou de esclarecer que o valor complementar a recolher deveria ser monetariamente atualizado.

Do voto condutor, colhe-se:

Desse modo, não tendo havido essa cautela do tribunal de origem, descabe aplicar a deserção que, configura verdadeira surpresa processual, na medida em que se decide a controvérsia acerca da complementação do preparo com base em critério não revelado anteriormente à parte prejudicada pela decisão. O princípio da não surpresa foi contemplado no enunciado normativo do artigo 10 do Código de Processo Civil de 2015. 


\title{
Personalidade Acadêmica Homenageada: \\ Augustus B. Cochran III (Agnes Scott College)
}

\author{
Em outro julgado o Superior Tribunal de Justiça ${ }^{4}$ também se manifestou \\ acerca da aplicação do princípio da não-surpresa preconizado pelo Art. 10 do \\ CPC/2015:
}

\begin{abstract}
EMBARGOS DE DECLARAÇÃO. OMISSÃO. OBSCURIDADE. CONTRADIÇÃO. INEXISTÊNCIA. PRINCÍPIO DA NÃO SURPRESA (ART. 10 DO CPC). AUSÊNCIA DE OFENSA. 1. Os embargos de declaração só se prestam a sanar obscuridade, omissão ou contradição porventura existentes no acórdão, não servindo à rediscussão da matéria já julgada no recurso. 2. O "fundamento" ao qual se refere o art. 10 do CPC/2015 é o fundamento jurídico - circunstância de fato qualificada pelo direito, em que se baseia a pretensão ou a defesa, ou que possa ter influência no julgamento, mesmo que superveniente ao ajuizamento da ação - não se confundindo com o fundamento legal (dispositivo de lei regente da matéria). A aplicação do princípio da não surpresa não impõe, portanto, ao julgador que informe previamente às partes quais os dispositivos legais passíveis de aplicação para o exame da causa. O conhecimento geral da lei é presunção jure et de jure. 3 . $O$ requisito do prequestionamento diz respeito apenas à fase de conhecimento do recurso especial. A orientação da Súmula 456 do STF ("O Supremo Tribunal Federal, conhecendo do recurso extraordinário, julgará a causa, aplicando o Direito à espécie") foi incorporada como texto legal expresso pelo art. 1034 do novo CPC, segundo o qual "Admitido o recurso extraordinário ou o recurso especial, o Supremo Tribunal Federal ou o Superior Tribunal de Justiça julgará o processo, aplicando o direito." 4. Embargos de declaração rejeitados.
\end{abstract}

Do acórdão, citam-se trechos que interessam ao presente artigo:

Se ao autor e ao réu não é exigido que declinem, na inicial e na contestação, o fundamento legal, mas apenas o fundamento jurídico, não faz sentido supor que o magistrado deva proferir despacho prévio à sentença enumerando todos os dispositivos legais possivelmente em tese aplicáveis para a solução da causa. Os fatos da causa devem ser submetidos ao contraditório, não o ordenamento jurídico, o qual é de conhecimento presumido não só do juiz (iura novit curia), mas de todos os sujeitos ao império da lei, conforme presunção jure et de jure (art. 3o da LINDB) (...) A aventada exigência de que o juiz submetesse a prévio contraditório das partes não apenas os fundamentos jurídicos, mas também os dispositivos legais (fundamento legal) que vislumbrasse de possível incidência, sucessivamente, em relação aos pressupostos processuais, condições da ação, prejudiciais de mérito e ao próprio mérito, inclusive pedidos sucessivos ou alternativos, entravaria o andamento dos processos,

\footnotetext{
${ }^{4}$ EDcl no REsp 1280825/RJ, Rel. Ministra MARIA ISABEL GALLOTTI, QUARTA TURMA, julgado em 27/06/2017, DJe 01/08/2017
} 


\title{
Personalidade Acadêmica Homenageada:
}

Augustus B. Cochran III (Agnes Scott College)

\begin{abstract}
conduzindo ao oposto da eficiência e celeridade desejáveis. Seria necessário exame prévio da causa pelo juiz, para que imaginasse todos os possíveis dispositivos legais em tese aplicáveis, cogitados ou não pelas partes, e a prolação de despacho submetendo artigos de lei - cujo desconhecimento não pode ser alegado sequer pelos leigos - ao contraditório, sob pena de a lei vigente não poder ser aplicada aos fatos objeto de debate na causa. A discussão em colegiado, com diversos juízes pensando a mesma causa, teria que ser paralisada a cada dispositivo legal aventado por um dos vogais, a fim de que fosse dada vista às partes. Grave seria o entrave a marcha dos processos, além de fértil campo de nulidades
\end{abstract}

Embora pareça restar claro que, ainda que, num primeiro momento, a invocação do princípio da não surpresa esteja voltada especialmente a discutir questões atinentes à processualidades tais como contraditório, ampla defesa e devido processo legal, a Lei de Introdução - LINDB, especificamente em seu artigo 24, pode ter trazido uma alteração no paradigma da aplicação da jurisprudência aos processos em curso, haja vista que, como se disse, uma leitura inicial do referido artigo dá a entender que se considere a jurisprudência da época dos fatos - e não aquela que verifica quando do efetivo julgamento.

Para Marinoni e Mitidiero: ${ }^{5}$

Não há Estado Constitucional e não há mesmo Direito no momento em que casos idênticos recebem diferentes decisões do Poder Judiciário. Insulta o bom senso que decisões judiciais possam tratar de forma desigual pessoas que se encontram na mesma situação.

Diante da inquestionável dificuldade da jurisprudência pátria encontrar sua desejável estabilidade, vêm à tona discussões tais quais se pretende, por este artigo, pincelar, em especial a segurança jurídica.

Aurélio Mota de Souza ${ }^{6}$ elabora interessante distinção entre segurança jurídica e certeza do direito. Segundo o autor:

\footnotetext{
${ }^{5}$ MARINONI, Luiz Guilherme; MITIDIERO, Daniel. O Projeto do CPC. Críticas e propostas. São Paulo: RT, 2010, p. $17-18$

${ }^{6}$ SOUZA, Carlos Aurélio Mota de. Segurança Jurídica e Previsibilidade. São Paulo: Editora LTR, 1996, p. 56.
} 
Personalidade Acadêmica Homenageada:

Augustus B. Cochran III (Agnes Scott College)

\begin{abstract}
A segurança é fato, algo concreto, objetivo, como uma rodovia em que um caminhante transita mesmo à noite, mas sabe que seus elementos, como a sinalização, o concreto do chão, as defensa laterais, Ihe dão a segurança de que, seguindo-a corretamente, chegará a seu destino. Já a certeza seria um valor, algo em que se pode confiar, sendo subjetiva, como acreditar que, seguindo corretamente a estrada, se alcançará o destino.
\end{abstract}

Interessante notar que o próprio CPC em vigor traz alguns dispositivos que emanam comandos aos tribunais no sentido de que mantenham suas jurisprudências íntegras, estáveis e coerentes e direciona aos Juízes determinação para que observem as decisões dos tribunais superiores, os enunciados de súmulas e as decisões em incidentes de resolução de demandas repetitivas (artigo 926, caput).

Em outra passagem, o Código de Processo Civil, reza que, além de observar as decisões proferidas anteriormente, os tribunais, ao alterarem o seu panorama jurisprudencial, o façam com a mais devida fundamentação (artigo 927 e seu parágrafo $4^{\circ}$ ).

Em artigo publicado pelo site do Conjur, Eurico di Santi assim expressa: ${ }^{7}$

O novo diploma obriga que as autoridades dotadas de poder de julgamento (judicial e administrativo), quando estiverem diante de normas de conteúdo indeterminado, primeiro, considerem as decisões passadas do Poder Judiciário e da administração pública antes de decretarem suas conclusões. Segundo, caso seja impossível manter o posicionamento sedimentado, que façam a passagem ao novo resultado de forma suave, necessariamente adotando um regime de transição.

De se notar que, diante de uma alteração que se considere brusca de entendimento jurisprudencial, a imposição de um "regime de transição" pode ser uma interessante ferramenta visando a segurança jurídica. Em outras palavras, quer parecer que o artigo 23 recentemente introduzido à LINDB objetiva permitir aos

${ }^{7}$ Artigo 23 da nova LINDB e a segurança jurídica para o contencioso do ágio. Disponível em: https://www.conjur.com.br/2018-mai-30/neffgv-lindb-seguranca-juridica-contencioso-agio?imprimir=1 Acesso em 03/12/2018 às 21:36 h. 
Personalidade Acadêmica Homenageada:

Augustus B. Cochran III (Agnes Scott College)

afetados pela alteração de entendimento dos tribunais um tempo para se adaptarem ao novo cenário de orientação, tratando-se, mutatis mutandis, de uma espécie de modulação temporal de efeitos. Neste ponto, aliás, não se pode furtar ao registro de que o art. 927, §3으 do $\mathrm{CPC} / 15^{8}$, versa que a técnica de modulação dos efeitos da decisão judicial seria uma fora de salvaguardar o "interesse social" bem como a "segurança jurídica".

\section{CONSIDERAÇÕES FINAIS}

Inicialmente deve-se sublinhar que a Lei de Introdução às Normas do Direito Brasileiro - LINDB projeta seus efeitos perante praticamente todas as áreas do Direito, não se limitando, por óbvio, ao Direito Civil.

Ao tocar em temas caros tais como o dever de motivação das decisões sejam estas proferidas na esfera administrativa ou mesmo judicial - e a celebração de compromisso da autoridade administrativa com interessados em eliminar incertezas, referida Lei procura, dentre seus mais variados intentos, parece pretender atribuir mais responsabilidade ao agente público na sua aplicação.

Ao Supremo Tribunal Federal cabe a função precípua de "guardião" da Constituição Federal. Não se olvide que a expressão precípua, tem com significados principal e essencial, fundamental, mas não exclusivo.

Isso quer dizer que a função de interpretar a Constituição - até pela via do controle difusos - cabe, não só aos tribunais judiciais, como também aos órgãos administrativos de julgamento.

O respeito aos precedentes (judiciais ou administrativos) - sendo estes compreendidos como decisões proferidas em caso concreto que servem de

8 § 30 Na hipótese de alteração de jurisprudência dominante do Supremo Tribunal Federal e dos tribunais superiores ou daquela oriunda de julgamento de casos repetitivos, pode haver modulação dos efeitos da alteração no interesse social e no da segurança jurídica. 
Personalidade Acadêmica Homenageada:

Augustus B. Cochran III (Agnes Scott College)

parâmetro ao julgamento de posteriores casos análogos - vem como a tônica de uma legislação bastante antiga, mas que nem por isso, apagou-se do centro das grandes discussões e reflexões jurídicas no País.

A observância aos precedentes, além de visar uma mitigação da ruptura com entendimentos tomados por determinados tribunais ou cortes, parece ter o propósito de resguardar a observância de um dos princípios mais propalados em matéria de Direito Público: a segurança jurídica.

Heleno Taveira Torres assim define o princípio da segurança jurídica: ${ }^{9}$

\begin{abstract}
Ciente destas cautelas, define-se o princípio da segurança jurídica tributária, em uma proposta funcional, como princípio-garantia constitucional que tem por finalidade projetar expectativas de confiança legítima nos atos de criação ou de aplicação de normas, mediante certeza jurídica, estabilidade do ordenamento e confiabilidade na efetividade de direitos e liberdades, assegurada como direito público fundamental.
\end{abstract}

Ressalva-se que o princípio da segurança jurídica, ainda que não ostente necessariamente um papel de hierarquia superior aos demais princípios, possui uma densidade que the autoriza ostentar a alcunha de sobreprincípio.

A respeito da uniformização da jurisprudência, como forma de preservação da segurança jurídica, afirmam Cruz, Meyer e Rodrigues: ${ }^{10}$

\begin{abstract}
Desde muito cedo, os operadores do direito americano estudam casos, eles leem $\mathrm{m}$ os votos e aprendem sobre essa lógica argumentativa case by case; diferentemente de nós, que não temos essa tradição, que lá é de mais de duzentos anos desse tipo de prática, o que permite identificar os argumentos e questões que podem ou não vincular um determinado caso, além, é claro, de o prece- dente poder ser superado. Assim, pode-se perceber que os americanos são preparados para proceder a uma superação de precedentes holding. No Brasil, o STF herda o papel de uniformização de jurisprudência, o que é uma ideia que veio dos assentamentos das Casas de Suplicação de Portugal e do Brasil. O papel do Supremo Tribunal Federal é de uniformizar jurisprudência, ele não quer
\end{abstract}

9 TORRES, Heleno Taveira. Direito constitucional tributário e segurança jurídica. São Paulo: RT, 2011. p. 186.

${ }^{10}$ CRUZ, Álvaro R. S.; MEYER, Emilio P. N; RODRIGUES, Eder B. Desafios contemporâneos do controle de constitucionalidade no Brasil. Belo Horizonte: Arraes, 2012. p. 87 e ss. 
Personalidade Acadêmica Homenageada:

Augustus B. Cochran III (Agnes Scott College)

\begin{abstract}
tratar de um direito concreto de alguém, e é por isso que ele faz a distinção entre questões de fato e de direito. O Supremo Tribunal Federal só aprecia questões de direito. No entanto, como separar direitos de fatos? Na prática o STF, e também o STJ, examinam o fato de forma direta ao admitirem os recursos extraordinário e especial. (...) A própria ideia de que o papel do STF é de mera uniformização da jurisprudência para garantir previsibilidade e segurança parece consentânea com uma ideia já bastante discutível no Direito Administrativo que é a manutenção da supremacia do interesse público.
\end{abstract}

Geraldo Ataliba pontua que a segurança jurídica, para o contribuinte, "impede que o estado faça o que deseja, quando quer, de qualquer modo". 11

Tanto o STJ quanto o STF têm reiterado o valor do trânsito julgado administrativo, que é a coisa julgada "segundum eventum litis", ou seja, coisa julgada segundo o resultado do processo, ou ainda que se opera apenas em face das circunstâncias da causa.

Nesse diapasão, quer parecer, situa-se a observância do princípio da não surpresa.

Por fim, cabe ressalvar, então, que o princípio da segurança jurídica visa tutelar direitos e garantias individuais, exatamente no sentido de outorgar proteção aos administrados pra que tenham o ato jurídico perfeito bem como a coisa julgada preservados, uma vez que tais primados foram erigidos pelo Constituinte de 1988 como cláusulas de pedra, não podendo, sequer, a deliberação de emenda tendente a aboli-los.

\title{
REFERÊNCIAS
}

BRASIL. Lei Federal n. 13.655 de 25/04/2018. Consulta em: http://www.planalto.gov.br/ccivil_03/_Ato2015-2018/2018/Lei/L13655.htm.

Lei Federal no 13.105, de 16/03/2015. Consulta em: http://www.planalto.gov.br/ccivil 03/ Ato2015-2018/2015/Lei/L13105.htm.

${ }^{11}$ ATALIBA, Geraldo. República e Constituição. 2. ed. São Paulo: Malheiros, 1988. 
Personalidade Acadêmica Homenageada:

Augustus B. Cochran III (Agnes Scott College)

\section{http://www.planalto.gov.br/ccivil 03/LEIS/L5172.htm.}

ATALIBA, Geraldo. República e Constituição. 2. ed. São Paulo: Malheiros, 1988.

CRUZ, Álvaro R. S.; MEYER, Emilio P. N; RODRIGUES, Eder B. Desafios contemporâneos do controle de constitucionalidade no Brasil. Belo Horizonte: Arraes, 2012.

DE SANTI, Eurico Marcos Diniz de Santi. Artigo 23 da nova LINDB e a segurança jurídica para 0 contencioso do ágio. Disponível em: https://www.conjur.com.br/2018-mai-30/neffgv-lindb-seguranca-juridica-contenciosoagio?imprimir=1. Acesso em 03/12/2018 às 21:36 h.

MARINONI, Luiz Guilherme; MITIDIERO, Daniel. O Projeto do CPC. Críticas e propostas. São Paulo: RT, 2010.

MARINS, James. Direito Processual Tributário Brasileiro. Administrativo e Judicial. 2 ed. em e-book baseada na 10. Ed. Impressa. Sai Paulo: Revista dos Tribunais, 2017.

SOUZA, Carlos Aurélio Mota de. Segurança Jurídica e Previsibilidade. São Paulo: Editora LTR, 1996.

TORRES, Heleno Taveira. Direito constitucional tributário e segurança jurídica. São Paulo: RT, 2011.

XAVIER, Alberto. Do lançamento - Teoria geral do ato, do procedimento e do processo tributário. São Paulo: Forense, 1998. 